\title{
Quality of Life in Children with Psychiatric Disorders at the Philippine Children's Medical Center (PCMC): Child, Parent and Clinician Report
}

\author{
Joy P. Malinit \\ Section of Child Psychiatry, Child Neuroscience Division, Philippine Children's Medical Center
}

\begin{abstract}
Objective. To determine quality of life (QoL) of children and adolescents with psychiatric disorders at PCMC using child, parent and clinician reports.

Methods. Consecutive referrals of 125 children and adolescents and their parents assessed QoL using the Pediatric Quality of life Inventory (PedsQL) and the Child and Adolescent Functional Assessment Scale (CAFAS) for clinicians.

Results. Eight diagnostic categories were identified: attention deficit hyperactivity disorder (ADHD), anxiety disorder, disruptive behavior disorders, mood disorder, no axis I diagnosis, psychotic disorder, parent-child relational problem, and others. From the children's report, no significant difference was noted in the QoL among diagnostic categories. From the parent's report, children with disruptive behavior disorders had the poorest psychosocial health. From the clinician's report, children with psychotic and mood disorders had the poorest QoL. Specific functional domains were affected per diagnostic category: for children with ADHD, school functioning; for children with anxiety disorders, mood functioning; for children with disruptive behavior disorder, home, community domains, and social and school functioning; for children with mood disorders, home, community, and self-harm domains; for children with psychotic disorder, behavior toward others, mood, thinking, and social domains.
\end{abstract}

Conclusions. Multi-rater assessment of QoL of children and adolescents varied. Domains of functioning must be targeted to improve overall QoL.

Key Words: pediatric psychiatric disorders, CAFAS: The Child and Adolescent Functional Assessment Scale, PedsQL: Pediatric Quality of Life Inventory 4.0, QoL: quality of life

Presented at the 13th NIH Anniversary Celebration and 9th University Science and Technology Week Celebration, February 11, 2011, Century Park Hotel.

Corresponding author: Joy P. Malinit, MD

Section of Child Psychiatry

Child Neuroscience Division

Philippine Children's Medical Center

Quezon Avenue, Quezon City, 1100 Philippines

Telephone: +632 9246601 loc 325/307

Email: joypmalinitmd@yahoo.com

\section{Introduction}

The determination of quality of life has recently been a major focus in patient care. Quality of life (QoL) encompasses not only clinical symptoms but also emphasizes the patient's functional adaptation in his or her context. ${ }^{1}$ QoL is a broad concept and quite difficult to define. A QoL definition that is simply based on symptomatic or biomedical indicators does not accurately describe the full impact of physical illness on children. ${ }^{2}$

Schmeck and Poustka, in 1997, defined QoL as a multidimensional concept that taps a person's subjective functioning and objective indicators. ${ }^{3}$ The subjective functioning includes the physical, emotional, and social functioning of the individual. ${ }^{4}$ The objective indicators include living conditions, employment or school functioning and social relationships..$^{5,6}$

What is the quality of life of pediatric patients with psychiatric health conditions? Most psychiatric illnesses tend to persist, thus improvement in the quality of everyday life can be considered an important treatment goal. ${ }^{3}$ Yet, in the local and international setting, little attention has been paid to QoL in children and adolescents with psychiatric disorders. There are no local studies on the quality of life of pediatric psychiatric patients.

\section{Significance of the Study}

There is a need, therefore, for this pioneering work that will investigate the QoL of pediatric patients with psychiatric conditions in the Philippines. Examining the impact of psychiatric diseases on different aspects of the QoL can aid clinicians in focusing on particular QoL domains during the diagnostic process. The assessment of the child's QoL facilitates the determination of treatment goals. ${ }^{1}$

QoL determination will help both the clinician and parent focus on the specific domains of function in which a child needs the most help. Specific interventions will then be geared toward improving these domains assessed to be impaired.

\section{Review of Literature}

There is no general consensus regarding a single definition of QoL, nor is there a gold standard for 
measurement. An approach to assess the quality of life utilizes questionnaire-based measurements.

The World Health Organization (WHO) in 1948 has stated that a health-related quality of life instrument for children must be multidimensional. ${ }^{7}$ It must consist of a minimum of the physical, mental, and social health generic core dimensions. Pediatric Quality of Life Inventory (PedsQL 4.0) is a brief and practical tool that may be used to assess the quality of life in children and adolescents with psychiatric disorders. PedsQL 4.0 has provisions for acquiring data from a child's parent or caregivers by its parallel parent-proxy report so that the patient will not be the lone source of information. ${ }^{8}$

D. Bastiaansen et al. studied the psychometric properties of the Dutch translation of the PedsQL 4.0 generic core scales and assessed its usefulness in measuring quality of life (QoL) in a child psychiatric population. ${ }^{9}$ The PedsQL seems a valid instrument in measuring QoL in children referred for psychiatric problems. The validity of PedsQL ${ }^{\text {TM }}$ as translated in Filipino for children with psychiatric conditions has been recently studied. ${ }^{10}$

In a previous study conducted on PEdsQL as Pediatric Population Health Measure, cut-off point scores for both child- and self-report and parent proxy-report were designated. ${ }^{11}$ A meaningful cut-off point score for an at-risk status for impaired HRQOL was a Total Scale Score of 69.7 (child self-report) and 65.4 (parent-proxy report).

The validity study done on the Filipino version of PedsQL also showed an at-risk status for impaired HRQoL for children and adolescents with psychiatric health conditions. Thus, there is a need to study more closely the HRQOL of these children. The study will specifically determine if the scores of the pediatric psychiatric patients in the PedsQL 4.0 tool fall into the designated at-risk status for impaired quality of life.

\section{Objectives of the Study}

General Objective

- To determine the quality of life (QoL) of children and adolescents with psychiatric disorders

\section{Specific Objectives}

- To determine the difference in the quality of life (QoL) of children with the most prevalent pediatric psychiatric disorders

- To compare the variation in the reported QoL in the child, parent, and clinician

- To determine the association of sociodemographic factors such as age, sex, education, economic status, and duration of illness with the quality of life of children and adolescents with psychiatric disorders

\section{Methods}

\section{Procedure and Participants}

The cross-sectional study was submitted for approval by the Office of Research Development of the Philippine Children's Medical Center (PCMC). After approval, recruitment of participants began.

The target respondents (125 children with their respective parents) consisted of consecutive referrals of children and adolescents aged 6 to 18 years who were seen at the outpatient child psychiatric clinics in PCMC. The participants were referred to the psychiatric clinics and diagnosed with a psychiatric disorder, including externalizing disorders (e.g., attention deficit hyperactivity disorder, conduct disorder, oppositional defiant disorder) or internalizing disorders (e.g., anxiety and mood), pervasive developmental disorders and other disorders of childhood.

The exclusion criteria were the following:

1) in-patients,

2) patients with co-morbid chronic medical illness,

3) mentally-incapacitated patients (i.e., mental retardation) unable to read and comprehend the questionnaire,

4) patients whose reality testing was assessed to be severely impaired through a formal mental status examination, and posed hindrance to questionnaire completion,

5) participants undergoing legal proceedings or litigation.

The investigator informed the children and their parents about the QoL study during their visit to the clinic and asked for their participation. Assent and informed consent were obtained from child and parents, respectively. Questionnaires were given for completion.

\section{Ethical Considerations}

\section{Subject Profile}

The target participants consisted of children and adolescents aged 6-18 years and their respective parents or caregivers. They were the respondents to the questionnairebased cross-sectional study.

The respondents came from consecutive referrals to the outpatient clinics of the Section of Child Psychiatry of the Philippine Children's Medical Center.

The investigator informed the children and their parents about the quality of life study during their visit to the clinic and will ask for their participation. They were oriented as to the purpose of the study, which served to seek how the children were functioning as to several domains (physical, emotional, social and school) for the past month. Informed consent and assent were obtained from the parents and children, respectively. 
The children and their parents/caregivers were asked to give a few minutes of their time to complete the PedsQL questionnaire. They were thanked after completion of the questionnaire and were told that their attending clinician will discuss the results with them.

From completion of the questionnaire, should there have been information or events that arose, relevant to the child's condition; those were to be relayed to the attending doctor so that the children and parents should have received support through counseling.

The parents and their children were asked to complete the questionnaires inside the privacy of the clinics. To adequately protect the confidentiality of the gathered data, coding, destruction of identifying information, limiting access to data to only the investigators were employed. The stored data were encrypted and the password protected.

The investigator processed the result of the questionnaire and gave feedback to the attending doctor as to the outcome (i.e. Total Scare Scores \& Psychosocial Health Summary Score and the specific the domains where the child's functioning is impaired). The attending clinician could have used the results to focus on treatment goals and interventions for the patient. The implementation of the specific interventions is beyond the scope of the study.

\section{Informed Consent}

A copy of the English and Filipino version of the informed consent and assent were provided in the research protocol.

\section{Measures}

Pediatric Quality of Life Inventory Version 4.0 (PedsQL). ${ }^{12}$ The Filipino version of the PedsQL was used to measure the child's QoL from the perspective of the child and parents.

The PedsQL had a child self-report and parallel parent proxy-report format and had different versions for ages 5 to 7,8 to 12,13 to 18 years of age. The items on each of the forms differed slightly in developmentally appropriate language or use of the first or third person.

The patient proxy-report format assessed the parent's perceptions of the child's QoL. The instructions in each question ask how much of a problem an item has been for the child during the past month.

The 23 items were scored on a 5-point Likert scale from 100 to $0(100=$ "never a problem"; 0 = "almost always a problem"; higher scores indicated a better QoL). Four subscales were computed from the 23 items, covering different dimensions of QoL:

(1) physical functioning (8 items; e.g., "hard to do sports or exercises")

(2) emotional functioning (5 items; e.g., "feel angry" or "feel afraid")

(3) social functioning (5 items; e.g., "trouble getting along with peers")
(4) school functioning (5 items; e.g., "trouble keeping up with school work")

A scale score was computed as the sum of the items divided by the number of items answered. A Psychosocial Health Summary Score and a Total Scale Score were also computed. The Psychosocial Health Summary Score (15 items) was the sum of items divided by the number of items answered in the emotional, social and school functioning subscales.

Child and Adolescent Functional Assessment Scale. The Child and Adolescent Functional Assessment Scale (CAFAS) was used to measure the child's QoL from the perspective of the clinician, working with the child and parents. ${ }^{13}$ It was designed to measure functional impairment across multiple domains in children and adolescents. Impairment was considered as the degree to which the child's problems interfered with his or her functioning in various life roles.

The child's functioning was rated on eight domains:

(1) Role Performance-School/Work

(1) Role Performance-Home

(2) Role Performance- Community

(3) Behavior Toward Others

(4) Moods/ Emotions

(5) Self-Harmful Behavior

(6) Substance Use

(7) Thinking

Each domain contained numerous behavioral descriptions, divided into four categories of impairment and scored as follows: 30-severe; 20- moderate; 10 - mild or 0 minimal or no impairment.

The rater determined for each domain the category that described the child's most severe level of dysfunction during the past 3 months. The eight domain scores were summed to yield a CAFAS Total Child Score, with a possible range from 0-240; higher scores indicated more impairment.

The following chart illustrates Dr. Kay Hodges's interpretation of a youth's total score: ${ }^{14}$

\begin{tabular}{|c|c|}
\hline & CAFAS Scoring: Total Score \\
\hline 8-Scale Sum & Description \\
\hline $0-10$ & No noteworthy impairment \\
\hline $20-40$ & Youth can likely be treated on an outpatient basis \\
\hline $50-90$ & $\begin{array}{l}\text { Youth may need additional services beyond } \\
\text { outpatient care }\end{array}$ \\
\hline $100-130$ & $\begin{array}{l}\text { Youth likely needs care which is more intensive } \\
\text { than outpatient and/or which includes multiple } \\
\text { sources of supportive care }\end{array}$ \\
\hline $140+$ & $\begin{array}{l}\text { Youth likely needs intensive treatment, the form of } \\
\text { which would be shaped by the presence of risk } \\
\text { factors } \mathcal{E} \text { resources available within the family } \mathcal{E} \\
\text { community }\end{array}$ \\
\hline
\end{tabular}


The PedsQL Filipino version and the CAFAS were used in tandem to obtain a multi-perspective centered, holistic evaluation from children, parents and the clinician viewpoints.

Patient Information Form. A patient information form was accomplished by the investigator. It contained the demographic information about the child and parents.

\section{Data Analysis}

Sex and age differences between diagnostic categories were analyzed using the $\mathrm{x}^{2}$ test and one-way analysis of variance (ANOVA).

Mean scale scores on questionnaires for the different diagnostic categories were compared using ANOVA. Difference in QoL indicators among the diagnostic categories were analyzed using the $\mathrm{x}^{2}$ test and ANOVA.

Pearson's correlation, chi-square and kappa statistics were computed to assess agreement between ratings of parents, children and clinician.

\section{Limitations of Approach}

The study did not include admitted pediatric psychiatric patients and therefore was reflective only of the most prevalent out-patient psychiatric disorders. An important factor that may affect the child's QoL, family functioning, was not measured.

The study focused on personal functioning and did not include the objective quality of life indicators.

\section{Results}

Table 1 presents a total of 125 children and adolescents who participated in the study. Of these children, 67\% $(n=84)$ were male respondents. There were eight primary diagnostic categories defined: attention deficit hyperactivity disorder (ADHD), anxiety disorder, disruptive behavior disorders, mood disorder, no axis I diagnosis, psychotic disorder, parent-child relational problem and other disorders.

The no axis I diagnosis category included children who did not have a mental health condition as defined in DSM-IV TR. These children were referred for preoperative counseling or psychological support.

The diagnostic category "others" encompassed a widerange of clinical conditions of varying nature.

ADHD $(40 \%)$, mood disorder $(16 \%)$, and anxiety disorder (14\%) ranked the top diagnostic categories.

Among the males, ADHD (35\%) was the most prevalent psychiatric condition; whereas for the females, it was psychotic (7\%) and anxiety (6\%) disorders.

ADHD had the young mean age of 8.3 years, while psychotic disorders occurred at the mean age of 14.7 years old.

Significantly, males tended to have ADHD more than the females. Females are more likely to have psychotic or anxiety disorders. ADHD patients are younger than patients with mood and psychotic disorders. Those individuals with psychotic disorders are older than those with no axis I diagnosis, disruptive behavior disorder and parent-child relational problem.

For ADHD, it is generally accepted that the disorder is more common in boys, at a ratio ranging from 2.5:1 to 5.6:1. ${ }^{15}$ This study presents a higher ratio of 7:1. ADHD is indeed more prevalent in boys with the ratio reported as high as 9:1.16

Higher rates of most anxiety disorders have been found in females relative to males as early as age $6 .{ }^{17}$ However, the epidemiology of each anxiety disorder may vary. Separation anxiety disorder has been reported to occur equally in boys and girls. ${ }^{15}$ The results of this study show more males afflicted with anxiety. This could be accounted for by the criterion that excluded subjects with legal considerations, as this population mostly had a type of anxiety condtion called posttraumatic stress disorder (PTSD). The British National Survey of Mental Health showed that with PTSD, girls show twice the rate of boys. ${ }^{18}$

For disruptive disorders, the male-to-female ratio varies from $3: 1$ to 5:1, depending on the age range studied. Specifically, gender difference decreases in adolescence because of the increased rate among girls. ${ }^{19}$ This study reflects the same finding that disruptive disorders are more common among boys.

For mood disorders, there are shifts in the findings on the male-to-female ratio. Hankin et al. found that depression is more common in boys than in girls, with the ratio as high as 5:1 before the age of 10 years. ${ }^{20}$ By adolescence, a reversal in the gender ratio is seen, which becomes consistent with the adult male-to-female ratio of 1:2. This study looked at mood disorders in general, finding that it is more common among boys than girls. However, it may be noteworthy to look into the male-to-female ratios of depressive and bipolar mood disorders among preadolescents and adolescents separately as current literature shows that the pattern of sex distribution changes.

For psychotic disorders, specifically schizophrenia, it appears that age may determine the sex ratio occurring in childhood. ${ }^{21}$ Although most studies have shown a higher male-to-female ratio, as age increases, the ratio tends to even out. $^{20}$ As with other studies that find slight female predominance, the findings of this study may be a crosssectional effect.

For parent-child relational problems, the study shows female predominance with a ratio of 2:3. Available data from the Great Smoky Mountain study recorded a weighted prevalence of $3.6 \%{ }^{22}$ Otherwise, there is dearth of information about the epidemiology of this diagnostic category.

A majority of the respondents (73.6\%) had a lone primary diagnosis. Only $25.6 \%$ of the respondents had another psychiatric co-morbidity and $1 \%$ presented with two 
Table 1. Number of Children and Sex Ratio per Diagnostic Category

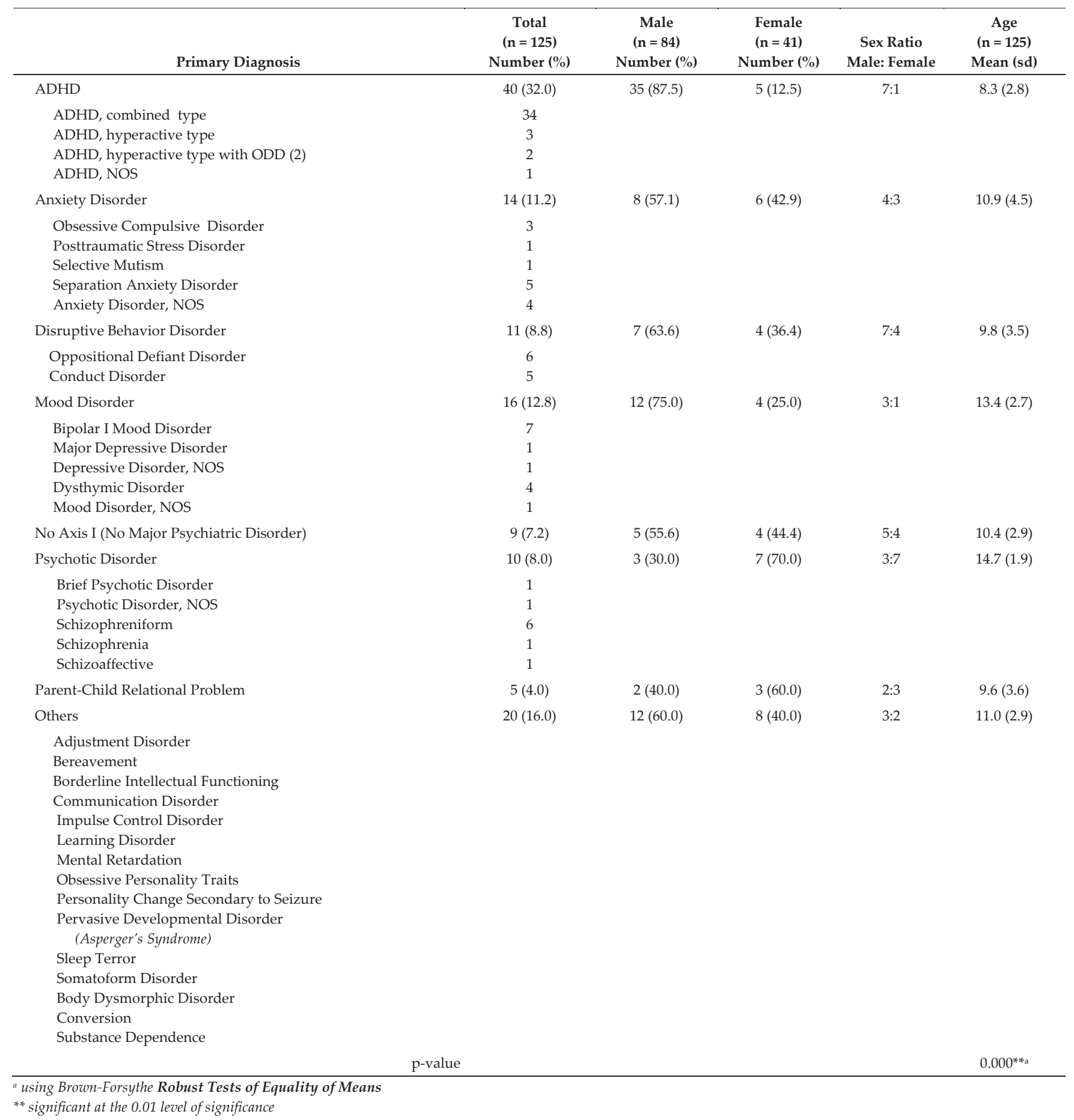

psychiatric co-morbidities. Sex has no significant association with having a co-morbid psychiatric condition (Table 2).

The mean scale scores by primary diagnostic categories did not significantly differ from one another $(p=0.162)$ in the child ratings for Psychosocial Health Summary and PedsQL Total Score (Table 3a). However, there is significant difference $(p=0.014)$ in the Psychosocial Health Summary Score from the parent ratings. Post-hoc tests of the parent report showed that children with No Axis I diagnosis had the relatively highest Psychosocial Health Summary score (mean= 72.41) and those with disruptive behavior disorder had the lowest score (mean=49.70) (Table 3b). 
Quality of Life in Children with Psychiatric Disorders in the Philippines

Table 2. Number of Children and Sex Distribution across Diagnostic Categories

\begin{tabular}{|c|c|c|c|}
\hline $\begin{array}{c}\text { Primary Diagnosis with } \\
\text { Co-morbidity }\end{array}$ & $\begin{array}{c}\text { Total } \\
(\mathrm{n}=125) \\
\text { Number }(\%)\end{array}$ & $\begin{array}{c}\text { Male } \\
(\mathrm{n}=84) \\
\text { Number }(\%)\end{array}$ & $\begin{array}{c}\begin{array}{c}\text { Female } \\
(\mathrm{n}=41)\end{array} \\
\text { Number }(\%)\end{array}$ \\
\hline $\begin{array}{l}\text { Primary Diagnosis with no } \\
\text { co-morbidity }\end{array}$ & $92(73.6)$ & $62(73.8)$ & $30(73.2)$ \\
\hline $\begin{array}{l}\text { Primary Diagnosis with } 1 \\
\text { co-morbidity }\end{array}$ & 32 (25.6) & $22(26.2)$ & $10(24.4)$ \\
\hline $\begin{array}{l}\text { Primary Diagnosis with } 2 \\
\text { co-morbidities }\end{array}$ & $1(0.8)$ & $0(0.0)$ & $1(2.4)$ \\
\hline p-value & & & $\begin{array}{r}0.353^{\mathrm{a}} / \\
0.889^{\mathrm{b}}\end{array}$ \\
\hline \multicolumn{4}{|c|}{$\begin{array}{l}\text { "using chi-square test (33.3\% of cells have expected frequency less than } 5 \text { ) } \\
b \text { using chi-square test with combined categories of primary diagnosis with co } \\
\text { morbidity (no significant association between primary diagnosis with co-morbidit } \\
\text { and gender) }\end{array}$} \\
\hline
\end{tabular}

By the Tukey HSD comparison, children with psychotic disorders (as rated by the child report) have significantly $(p=0.013)$ lower social functioning scale scores $($ mean $=44)$ in the PedsQL Inventory than those with disruptive behavior disorder, mood disorder and relational problem (Table 4).

Table 3b. Post Hoc Tests using Tukey HSD (Psychosocial Health Summary Score-Parent Report)

\begin{tabular}{lrcr}
\hline \multicolumn{4}{c}{ Psychosocial Health Summary Score } \\
\hline \multirow{2}{*}{ Primary Diagnosis } & N & Subset for alpha $=\mathbf{0 . 0 5}$ & $\mathbf{1}$ \\
\hline Disruptive Behavior Disorder & 11 & 49.70 & \\
Mood Disorder & 16 & 53.96 & 53.96 \\
Anxiety Disorder & 14 & 56.32 & 56.32 \\
Psychotic Disorder & 8 & 56.32 & 56.32 \\
ADHD & 40 & 57.60 & 57.60 \\
Others & 20 & 61.35 & 61.35 \\
Relational Problem & 5 & 69.33 & 69.33 \\
No Axis I & 9 & & 72.41 \\
Sig. & & .054 & .087
\end{tabular}

Means for groups in homogeneous subsets are displayed.

a. Uses Harmonic Mean Sample Size $=10.870$.

Table 3a. PedsQL Scores by Primary Diagnostic Categories

\begin{tabular}{|c|c|c|c|c|c|c|}
\hline Primary Diagnosis & $\mathbf{N}$ & $\begin{array}{l}\text { Psychosocial Health } \\
\text { Summary Score } \\
\text { (Child Report) }\end{array}$ & $\begin{array}{l}\text { PedsQL Total Scale Score } \\
\text { (Child Report) }\end{array}$ & $\mathbf{N}$ & $\begin{array}{l}\text { Psychosocial Health } \\
\text { Summary Score } \\
\text { (Parent Report) }^{\mathrm{c}}\end{array}$ & $\begin{array}{c}\text { PedsQL Total Scale } \\
\text { Score } \\
\text { (Parent Report) }\end{array}$ \\
\hline & & Mean (sd) & Mean (sd) & & Mean (sd) & Mean (sd) \\
\hline ADHD & 40 & $64.9(16.0)$ & $69.0(14.6)$ & 40 & $57.6(11.1)$ & $60.2(10.8)$ \\
\hline Anxiety Disorder & 14 & $57.9(17.2)$ & $63.1(13.0)$ & 14 & $56.4(20.8)$ & $60.8(18.0)$ \\
\hline Disruptive Behavior Disorder & 11 & $63.3(15.7)$ & $65.2(15.8)$ & 11 & $49.7(16.5)$ & $57.6(14.5)$ \\
\hline Mood Disorder & 16 & $67.3(14.6)$ & $69.8(15.3)$ & 16 & $54.0(15.4)$ & $58.9(14.2)$ \\
\hline No Axis I & 9 & $63.1(12.2)$ & $63.2(13.2)$ & 9 & $71.8(15.8)$ & $69.6(15.9)$ \\
\hline Psychotic Disorder & 10 & $49.7(16.7)$ & $54.4(15.3)$ & 10 & $51.7(19.7)$ & $61.4(17.6)$ \\
\hline Relational Problem & 5 & $66.0(14.6)$ & $61.5(11.8)$ & 5 & $69.3(12.4)$ & $71.7(9.1)$ \\
\hline Others & 18 & $62.5(15.1)$ & $65.8(13.5)$ & 20 & $62.4(13.2)$ & $65.5(12.4)$ \\
\hline Total & 123 & $62.6(15.8)$ & $65.7(14.6)$ & 125 & $58.1(15.6)$ & $62.0(13.8)$ \\
\hline $\mathrm{p}$-value & & $0.162^{\mathrm{a}}$ & $0.161^{\mathrm{a}}$ & & $0.014^{* a}$ & $0.243^{\mathrm{a}}$ \\
\hline
\end{tabular}

a using ANOVA F-test

${ }^{b}$ using Brown-Forsythe Robust Tests of Equality of Means

${ }^{c}$ psychotic disorder has 9 and others has 19 entries

Table 4. Mean Scale Scores on PedsQL Child Self-Report for Different Diagnostic Categories

\begin{tabular}{|c|c|c|c|c|c|c|c|}
\hline \multirow{3}{*}{ Primary Diagnosis } & \multirow{3}{*}{$\mathbf{N}$} & \multicolumn{6}{|c|}{ Pediatric Quality of Life Inventory (Child) } \\
\hline & & $\begin{array}{l}\text { Total Score } \\
(n=123)\end{array}$ & $\begin{array}{c}\text { Psychosocial } \\
\text { Health } \\
(n=123)\end{array}$ & $\begin{array}{c}\text { Physical } \\
\text { Functioning } \\
(\mathrm{n}=123)\end{array}$ & $\begin{array}{l}\text { Emotional } \\
\text { Functioning } \\
(n=123)\end{array}$ & $\begin{array}{c}\text { Social } \\
\text { Functioning } \\
(n=123)\end{array}$ & $\begin{array}{c}\text { School } \\
\text { Functioning } \\
\left(\mathrm{n}=122^{\mathrm{a}}\right)\end{array}$ \\
\hline & & Mean (sd) & Mean (sd) & Mean (sd) & Mean (sd) & Mean (sd) & Mean (sd) \\
\hline ADHD & 40 & $69.0(14.6)$ & $64.9(16.0)$ & $76.6(19.8)$ & $62.5(24.1)$ & $71.2(21.9)$ & $60.9(18.7)$ \\
\hline Anxiety Disorder & 14 & $63.1(13.0)$ & $57.9(17.2)$ & $73.0(13.8)$ & $47.1(18.5)$ & $65.0(29.5)$ & $61.4(18.0)$ \\
\hline Disruptive Behavior Disorder & 11 & $65.2(15.8)$ & $63.3(15.7)$ & $68.8(20.3)$ & $55.9(20.8)$ & $75.9(20.6)$ & $58.2(19.2)$ \\
\hline Mood Disorder & 16 & $69.8(15.3)$ & $67.3(14.6)$ & $74.6(22.3)$ & $61.9(20.6)$ & $76.6(16.2)$ & $63.4(16.1)$ \\
\hline No Axis I & 9 & $63.2(13.2)$ & $63.1(12.2)$ & $63.5(16.6)$ & $56.7(14.8)$ & $71.7(18.2)$ & $64.4(18.4)$ \\
\hline Psychotic Disorder & 10 & $54.4(15.3)$ & $49.7(16.7)$ & $63.3(19.6)$ & $45.0(26.0)$ & $44.0(26.0)$ & $60.0(21.1)$ \\
\hline Relational Problem & 5 & $61.5(11.8)$ & $66.0(14.6)$ & $53.1(10.6)$ & $51.0(22.2)$ & $80.0(12.7)$ & $67.0(22.8)$ \\
\hline Others & 18 & $65.8(13.5)$ & $62.5(15.1)$ & $71.9(15.9)$ & $53.9(19.5)$ & $69.2(18.9)$ & $64.5(15.4)$ \\
\hline Total & 123 & $65.7(14.6)$ & $62.6(15.8)$ & $71.6(19.0)$ & $56.5(22.0)$ & $69.5(22.6)$ & $62.0(17.8)$ \\
\hline p-value & & $0.161^{\mathrm{x}}$ & $0.162^{x}$ & $0.102^{\mathrm{x}}$ & $0.197^{x}$ & $0.013^{* x}$ & $0.972^{x}$ \\
\hline
\end{tabular}

a diagnosis 'no axis I' only have 8 entries

${ }^{x}$ using ANOVA F test

* ANOVA F test is significant at the .05 level 
Table 5. Mean Scale Scores on PedsQL Parent Proxy-Report for Different Diagnostic Categories

\begin{tabular}{|c|c|c|c|c|c|c|c|}
\hline \multirow[b]{2}{*}{ Primary Diagnosis } & \multirow[b]{2}{*}{$\mathbf{n}$} & \multicolumn{6}{|c|}{ Pediatric Quality of Life Inventory (Parent) } \\
\hline & & $\begin{array}{l}\text { Total Score } \\
(n=125)\end{array}$ & $\begin{array}{c}\text { Psychosocial } \\
\text { Health } \\
\left(\mathrm{n}=\mathbf{1 2 3}^{\mathrm{b}}\right) \\
\text { Mean (sd) }\end{array}$ & $\begin{array}{c}\text { Physical } \\
\text { Functioning } \\
\text { (n= 125) } \\
\text { Mean (sd) }\end{array}$ & $\begin{array}{c}\text { Emotional } \\
\text { Functioning } \\
(\mathrm{n}=124 \mathrm{c}) \\
\text { Mean (sd) }\end{array}$ & $\begin{array}{c}\text { Social } \\
\text { Functioning } \\
\left(\mathrm{n}=\mathbf{1 2 4}^{\mathrm{d}}\right) \\
\text { Mean (sd) }\end{array}$ & $\begin{array}{c}\text { School } \\
\text { Functioning } \\
\left(\mathrm{n}=\mathbf{1 2 1}^{\mathrm{e}}\right) \\
\text { Mean (sd) }\end{array}$ \\
\hline ADHD & 40 & $60.2(10.8)$ & $57.6(11.1)$ & $65.3(17.6)$ & $60.9(15.1)$ & $58.9(18.0)$ & $52.8(11.3)$ \\
\hline Anxiety Disorder & 14 & $60.8(18.0)$ & $56.4(20.8)$ & $69.2(17.8)$ & $48.9(27.0)$ & $66.3(25.3)$ & $53.9(21.5)$ \\
\hline Disruptive Behavior Disorder & 11 & $57.6(14.5)$ & $49.7(16.5)$ & $72.4(15.7)$ & $56.4(20.1)$ & $53.6(25.0)$ & $39.1(15.1)$ \\
\hline Mood Disorder & 16 & $58.9(14.2)$ & $54.0(15.4)$ & $68.2(17.7)$ & $50.6(20.2)$ & $61.2(19.9)$ & $50.0(16.7)$ \\
\hline No Axis I & 9 & $69.6(15.9)$ & $71.8(15.8)$ & $65.6(18.9)$ & $71.1(22.9)$ & $78.3(19.8)$ & $65.0(15.1)$ \\
\hline Psychotic Disorder & 10 & $61.4(17.6)$ & $51.7(19.7)$ & $71.9(12.2)$ & $38.5(23.6)$ & $59.5(29.0)$ & $61.7(15.0)$ \\
\hline Relational Problem & 5 & $71.7(9.1)$ & $69.3(12.4)$ & $76.2(7.8)$ & $55.0(23.5)$ & $84.0(9.6)$ & $69.0(16.4)$ \\
\hline Others & 20 & $65.5(12.4)$ & $62.4(13.2)$ & $71.7(14.4)$ & $51.2(12.1)$ & $69.3(22.2)$ & $66.6(21.5)$ \\
\hline \multirow[t]{2}{*}{ Total } & 125 & $62.0(13.8)$ & $58.1(15.6)$ & $68.7(16.3)$ & $55.1(20.1)$ & $63.6(22.1)$ & $55.6(17.9)$ \\
\hline & & $0.243^{x}$ & $0.014^{* x}$ & $0.692^{x}$ & $0.040^{* y}$ & $0.040^{* x}$ & $0.000^{* * x}$ \\
\hline
\end{tabular}

${ }^{b}$ psychotic disorder has 9 and others has 19 entries

c psychotic disorder has 9 entries

"others has 19 entries

e ADHD has 39, no axis I has 8, psychotic disorder has 9 and others has 19 entries only

x using ANOVA F test

y using Brown-Forsythe Robust Test of Equality of Means

* significant at the 05 level of significance

** significant at the 01 level of significance

Table 6. Characteristics of Patients by CAFAS Category

\begin{tabular}{|c|c|c|c|c|c|}
\hline \multirow{2}{*}{ Characteristics } & \multicolumn{5}{|c|}{ CAFAS Degree of Impairment/Level of Intervention } \\
\hline & Unimpaired & OPD basis & OPD and services & Additional supportive care & Intensive Management \\
\hline Mean Age (yrs) & 10.14 & 8.85 & 10.54 & 13.14 & 14.20 \\
\hline \multicolumn{6}{|l|}{ Gender } \\
\hline Female (41) & $2(4.9 \%)$ & $14(34.1 \%)$ & $17(41.5 \%)$ & $6(14.6 \%)$ & $2(4.9 \%)$ \\
\hline Male (84) & $5(6.0 \%)$ & $28(33.3 \%)$ & $33(39.3 \%)$ & $15(17.9 \%)$ & $3(3.6 \%)$ \\
\hline \multicolumn{6}{|l|}{ School Type } \\
\hline Out of school (6) & $0(0.0 \%)$ & $0(0.0 \%)$ & $2(33.3 \%)$ & $3(50.0 \%)$ & $1(16.7 \%)$ \\
\hline Private $(70)$ & $4(5.7 \%)$ & $25(35.7 \%)$ & $33(47.1 \%)$ & $6(8.6 \%)$ & $2(2.9 \%)$ \\
\hline Public (49) & $3(6.1 \%)$ & $17(34.7 \%)$ & $15(30.6 \%)$ & $12(24.5 \%)$ & $2(4.1 \%)$ \\
\hline Mean duration of illness (yrs) & 2.46 & 2.37 & 2.43 & 2.37 & 1.42 \\
\hline \multicolumn{6}{|l|}{ Presence of co-morbidity } \\
\hline None $(92)$ & $6(6.5 \%)$ & $34(37.0 \%)$ & $38(41.3 \%)$ & $10(10.9 \%)$ & $4(4.3 \%)$ \\
\hline At least 1 (33) & $1(3.0 \%)$ & $8(24.2 \%)$ & $12(36.4 \%)$ & $11(33.3 \%)$ & $1(3.0 \%)$ \\
\hline Mean CPedsQL & 58.33 & 68.08 & 67.16 & 63.45 & 56.09 \\
\hline Mean PPedsQL & 63.29 & 64.82 & 62.05 & 57.39 & 64.57 \\
\hline
\end{tabular}

Parents significantly scored $(p=0.014)$ children with disruptive behavior disorder to have lower Psychosocial Health Summary Score (mean=49.7) than those with no axis I diagnosis (mean=71.8) (Table 5). Patients with psychotic disorders have lower scores (mean= 38.5 ) in the domain of emotional functioning than those with no axis I diagnosis (mean=71.1). Children with disruptive behavior disorder had lower scores in social functioning (mean=53) compared to those with no axis I diagnosis (mean=78.3) and parentchild relational problem (mean=84).
Moreover, parents rated those with disruptive behavior disorder to have lower scores in the domain of school functioning (mean=39.1) than those with psychotic disorder (mean 61.7), no axis I diagnosis (mean=65), and parent-child relational problem (mean=69).

In CAFAS, the degree of intervention recommended is based on score severity. The first category of children (with scores 0-10) are those who may not have noteworthy impairment but are referred to health professionals. The next group of children (with scores 20-40) requires outpatient services. Those who scored 50-90 require outpatient care 
Quality of Life in Children with Psychiatric Disorders in the Philippines

Table 7a. Mean Scale Scores on CAFAS for Different Diagnostic Categories

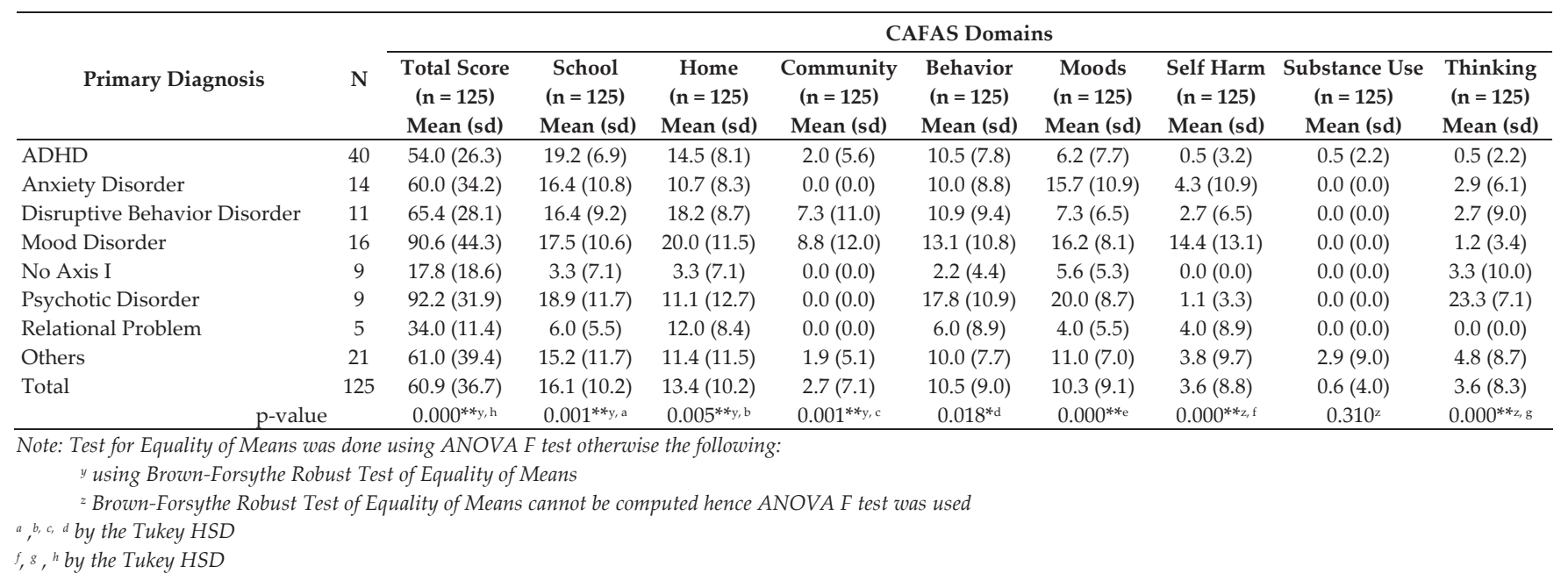

with additional services of a supportive nature. For children with 100-130 CAFAS scores, they need care which is more intensive than outpatient and/or includes multiple sources of supportive care. The last group of children who scored $>140$ need very intensive services that maybe in residential or inpatient settings at some point (Table 6).

The mean age of children assessed by CAFAS to need OPD services is 8.5 years old. In contrast, those categorized to require intensive management is older at 14.20 years old.

Most patients (39.3\% of males, $41.5 \%$ of females) need more than OPD care. Among out-of-school children, 50\% need additional supportive care; $47 \%$ of children enrolled in private schools need OPD and additional services; $34.7 \%$ of children enrolled in public schools need OPD services.

For the children identified to require intensive management, their mean duration of illness is 1.42 years. The unimpaired children, in comparsion, had 2.46 mean years of their condition. The relatively shorter mean duration of illness for those with more severe level of impairment may be related to the nature of the burden of the disease.

A total of $41.3 \%$ of children without co-morbidity need beyond OPD care. Of the children with at least one comorbidity, $69.7 \%$ needed additional services. This finding is reasonable as co-morbidity usually implies a more intense level of intervention.

The highest mean CPedsQL (child report) score of 68.08 was identified in the CAFAS to need OPD services. The lowest mean CpedsQL (child report) score of 56.09 was categorized to need intensive management. These findings are again congruent since lower PedsQL scores indicate more impairment that reasonably warrants higher level of intervention.

From the parent report, the lowest mean PPedsQL score of 57.39 was identified in the CAFAS to need additional supportive care. The highest mean PPedsQL score of 64.82 needed OPD services only. This PPedsQL mean (64.82) stands sensibly proximate to the identified cut-off point (65.4) for at risk-status of impairment from the parent report of prior health related quality of life studies.

The mean CAFAS scores show highly significant differences $(p=0.000)$ related to the type of diagnosis across almost all the functional domains (Table 7a).

The highest CAFAS scores are seen in respondents with psychotic and mood disorders (mean=92.2 and 90.62, respectively). The lowest CAFAS scores belong to children in the no axis I diagnostic category (mean=17.8).

In CAFAS total and subscale scores, the higher the score, the higher the level of functional impairment in the domain of functioning being assessed. Conversely, the lower the scores, the lower is the level of functional impairment.

The results of the CAFAS, as scored by the clinician per domain, are as follows (Table $7 \mathrm{~b}$ ):

Table 7b. Post Hoc Tests using Tukey HSD (for CAFAS)

\begin{tabular}{|c|c|c|c|c|}
\hline \multirow{3}{*}{ Primary Diagnosis } & \multirow{3}{*}{$\mathbf{N}$} & \multicolumn{3}{|c|}{ CAFAS Scores } \\
\hline & & \multicolumn{3}{|c|}{ Subset for alpha $=0.05$} \\
\hline & & 1 & 2 & 3 \\
\hline No Axis I & 9 & 17.78 & & \\
\hline Relational Problem & 5 & 34.00 & 34.00 & \\
\hline ADHD & 40 & 54.00 & 54.00 & 54.00 \\
\hline Anxiety Disorder & 14 & 60.00 & 60.00 & 60.00 \\
\hline Others & 21 & & 60.95 & 60.95 \\
\hline Disruptive Behavior Disorder & 11 & & 65.45 & 65.45 \\
\hline Mood Disorder & 16 & & & 90.62 \\
\hline Psychotic Disorder & 9 & & & 92.22 \\
\hline Sig. & & .050 & .304 & .107 \\
\hline \multicolumn{5}{|c|}{ Means for groups in homogeneous subsets are displayed. } \\
\hline \multicolumn{5}{|c|}{ a. Uses Harmonic Mean Sample Size = 11.116. } \\
\hline
\end{tabular}

Patients with no axis I diagnosis have lower subscale score $($ mean $=17.8)$ in the domain of school compared to 
Quality of Life in Children with Psychiatric Disorders in the Philippines

Table 8. Distribution of CAFAS Levels of Impairment/Intervention across Primary Diagnostic Categories

\begin{tabular}{|c|c|c|c|c|c|c|}
\hline \multirow[b]{2}{*}{ Primary Diagnosis } & \multicolumn{6}{|c|}{ CAFAS Degree of Impairment/Level of Intervention } \\
\hline & Unimpaired & OPD basis & OPD and services & $\begin{array}{c}\text { Additional } \\
\text { supportive care }\end{array}$ & $\begin{array}{c}\text { Intensive } \\
\text { Management }\end{array}$ & Total \\
\hline ADHD & $1(2.5 \%)$ & $16(40.0 \%)$ & $20(50.0 \%)$ & $3(7.5 \%)$ & $0(0.0 \%)$ & 40 \\
\hline Anxiety Disorder & $0(0.0 \%)$ & $5(35.7 \%)$ & $5(35.7 \%)$ & $4(28.6 \%)$ & $0(0.0 \%)$ & 14 \\
\hline Disruptive Behavior Disorder & $0(0.0 \%)$ & $3(27.3 \%)$ & $5(45.5 \%)$ & $3(27.3 \%)$ & $0(0.0 \%)$ & 11 \\
\hline Mood Disorder & $1(6.2 \%)$ & $2(12.5 \%)$ & $5(31.2 \%)$ & $6(37.5 \%)$ & $2(12.5 \%)$ & 16 \\
\hline No Axis I & $5(55.6 \%)$ & $3(33.3 \%)$ & $1(11.1 \%)$ & $0(0.0 \%)$ & $0(0.0 \%)$ & 9 \\
\hline Psychotic Disorder & $0(0.0 \%)$ & $0(0.0 \%)$ & $7(70.0 \%)$ & $1(10.0 \%)$ & $2(20.0 \%)$ & 10 \\
\hline Relational Problem & $0(0.0 \%)$ & $4(80.0 \%)$ & $1(20.0 \%)$ & $0(0.0 \%)$ & $0(0.0 \%)$ & 5 \\
\hline Others & $0(0.0 \%)$ & $9(45.0 \%)$ & $6(30.0 \%)$ & $4(20.0 \%)$ & $1(5.0 \%)$ & 20 \\
\hline
\end{tabular}

patients with other primary diagnoses except those with parent-child relational problems and the others diagnostic category. "This means that they have less impairment in terms of school functioning compared with the other diagnostic categories.

Patients with parent-child relational problems have lower subscale score (mean= 34.0) in the domain of school than those with psychotic disorders or ADHD. ${ }^{a}$ Therefore, like the children with no axis I diagnosis, these children with relational problem have less impairment in school functioning.

Patients with no axis I have lower subscale scores (mean= 3.3) in the domain of home (less impairment) than those with disruptive behavior disorder or mood disorder. ${ }^{\mathrm{b}}$

Patients with mood disorders have higher subscale score $($ mean $=8.8)$ in the domain of community (more impairment) than all others except those with disruptive behavior disorders, ADHD, or others. ${ }^{c}$

Patients with psychotic disorders have higher subscale scores (mean $=17.8$ ) in the domain of behavior (more impairment) than those with parent-child relational problem or no axis I diagnosis. ${ }^{\mathrm{d}}$

Patients with parent-child relational problem have lower subscale scores (mean= 4.0) in the domain of mood (less impairment) than those with anxiety disorders, mood disorders or psychotic disorders. In turn, those with no axis I diagnosis have lower scores (mean= 5.6) in the mood domain (less impairment) than those with mood disorders or psychotic disorders. Moreover, those with ADHD have lower scores (mean $=6.2$ ) in the domain of mood (less impairment) than those with psychotic disorder. ${ }^{\mathrm{e}}$

Patients with mood disorders have higher subscale scores (mean= 14.4) in the domain of self-harm (more impairment) than all others except those with anxiety disorders. ${ }^{f}$

Patients with psychotic disorders have higher subscale scores (mean $=23.3$ ) in the thinking domain (more impairment) compared to rest of the diagnostic categories. ${ }^{g}$

Patients with no axis I diagnosis have lower total CAFAS scores (mean=17.8), which signifies overall less impairment in functioning than those belonging to the diagnostic category of others, disruptive behavior disorders, mood disorders, or psychotic disorders.

Those with parent-child relational problem have lower total CAFAS scores (less impairment) than those with mood or psychotic disorder. ${ }^{\text {h }}$

Based on the CAFAS results, $50 \%$ of children with ADHD need additional services beyond outpatient care. For those with anxiety disorders, majority need to receive outpatient care. For children with disruptive behavior disorders, the level of intervention varies from outpatient treatment $(27.3 \%)$ to additional services beyond outpatient care $(45.5 \%)$ and additional supportive care $(27.3 \%)$ (Table 8).

Rationally, 55\% of children with no axis I diagnosis are categorized by CAFAS as unimpaired. In $70 \%$ of children with psychotic disorders, the level of intervention is determined to be additional services beyond outpatient treatment; $10 \%$ of psychotic children need more intensive than outpatient care and $20 \%$ need intensive care.

In the group with parent-child relational problems, $80 \%$ are deemed to require outpatient services only.

In general, children and adolescents with mood and psychotic disorders are those recommended to need more intensive management.

From the above results, the two groups (children with unimpaired and impaired quality of life) are significantly different only in CAFAS mean score. This is expected since the distinction of impairment and unimpairment was based on the CAFAS score interpretation. The results also showed having impaired or unimpaired quality of life is not associated with any of the demographic characteristics such as age, gender, school type, living situation, parent's work status and presence of co-morbidity (Table 9).

No significant correlation exists between child report of PedsQL (CPedsQL) and parent report of PedsQL (PPedsQL) and gender (Table 10a1).

Overall, significant correlation was found only between CAFAS and parent report of PedsQL (PPedsQL) (Table 10a2). Among males there were two significant correlations: the correlation between CAFAS and parent report of PedsQL (PPedsQL) and the correlation between CAFAS and child report of PedsQL (CPedsQL). 
Table 9. Differences between Children with Impaired and Unimpaired Quality of Life

\begin{tabular}{|c|c|c|c|c|}
\hline & Unimpaired & Impaired & $\begin{array}{l}\text { Value of } \\
\text { Statistic }\end{array}$ & p-value \\
\hline Mean Age (yrs) & 10.14 & 10.57 & $0.303^{\mathrm{a}}$ & 0.76 \\
\hline Gender (no.) & & & $1.00^{\mathrm{b}}$ & 0.58 \\
\hline Female & $2(5 \%)$ & $39(95 \%)$ & & \\
\hline Male & $5(6 \%)$ & $79(94 \%)$ & & \\
\hline School Type & & & $0.38^{\mathrm{b}}$ & 0.83 \\
\hline Out of school & $0(0 \%)$ & $6(100 \%)$ & & \\
\hline Private & $4(6 \%)$ & $66(94 \%)$ & & \\
\hline Public & $3(6 \%)$ & $46(94 \%)$ & & \\
\hline Living with/in & & & $3.62^{b}$ & 0.46 \\
\hline Both parents & $5(8 \%)$ & $62(92 \%)$ & & \\
\hline Mother only & $0(0 \%)$ & $27(100 \%)$ & & \\
\hline Father only & $1(17 \%)$ & $5(83 \%)$ & & \\
\hline Relatives & $1(4 \%)$ & $22(96 \%)$ & & \\
\hline Institution & $0(0 \%)$ & $2(100 \%)$ & & \\
\hline Parents' Work Status & & & $0.899^{b}$ & 0.83 \\
\hline Both Parents Unemployed & $0(0 \%)$ & $6(100 \%)$ & & \\
\hline Only 1 Parent Working & $4(7 \%)$ & $54(93 \%)$ & & \\
\hline Both Parents Working & $3(6 \%)$ & $52(94 \%)$ & & \\
\hline In Institution & $0(0 \%)$ & $6(100 \%)$ & & \\
\hline Presence of co-morbidity & & & $0.56^{\mathrm{b}}$ & 0.67 \\
\hline none & $6(7 \%)$ & $86(93 \%)$ & & \\
\hline at least 1 & $1(3 \%)$ & $32(97 \%)$ & & \\
\hline $\begin{array}{l}\text { Mean duration of illness } \\
\text { (yrs) }\end{array}$ & 2.46 & 2.35 & $-0.140^{\mathrm{a}}$ & 0.889 \\
\hline Mean CPedsQL & 58.33 & 66.34 & $1.417^{\mathrm{a}}$ & 0.159 \\
\hline Mean PPedsQL & 63.29 & 62.31 & $-0.182^{\mathrm{a}}$ & 0.856 \\
\hline Mean CAFAS & 5.71 & 64.83 & $125^{\mathrm{a}}$ & $<0.001^{* *}$ \\
\hline
\end{tabular}

CAFAS is mildly negatively correlated with parent report of PedsQL (PPedsQL). The higher the CAFAS score, the lower the PPedsQL score. Likewise, the lower the CAFAS score (less impaired), the higher the PPedsQL score (better quality of life).

Among males, CAFAS is mildly negatively correlated with parent report of PedsQL (PPedsQL). The higher the CAFAS score, the lower the PPedsQL score.

With the child report of PedsQL (CPedsQL) and CAFAS correlation, an inverse relationship exists. The higher the CAFAS score (more impaired), the lower the CPedsQL score (poorer quality of life). The converse is again applicable.

No significant correlation was found between duration of illness with any of PPedsQL, CPedsQL and CAFAS be it on the overall, among males only or among females only (Table 10b).

Significant correlation was found between CAFAS and CPedsQL among those with a single co-morbidity (Table 10c). CAFAS is mildly negatively correlated with CPedsQL among those with at least one co-morbidity. Among those with at least one co-morbidity, the higher the CAFAS score, the lower the CPedsQL score and vice versa.

No significant correlation was found between duration of illness with any of PPedsQL, CPedsQL and CAFAS be it on the overall, among those without co-morbidities only or among those with at least a single co-morbidity only (Table $10 \mathrm{~d})$.

As to the agreement among the different informants, results show that no significant agreement between the child and parent's report of an impaired or non-impaired quality of life (Table 11).

Likewise, there exists no significant agreement between the child's assessment of his or her own quality of life with

Table 10a. Correlation of PedsQL, CAFAS and Selected Characteristics

Table 10a1. By Gender

\begin{tabular}{|c|c|c|c|c|c|c|c|c|c|}
\hline & \multicolumn{9}{|c|}{ Child Report PedsQL (CPedsQL) } \\
\hline & \multicolumn{3}{|c|}{ All } & \multicolumn{3}{|c|}{ Female } & \multicolumn{3}{|c|}{ Male } \\
\hline & $\mathbf{N}$ & Pearson's rho & p-value & $\mathbf{N}$ & Pearson's Rho & p-value & $\mathbf{N}$ & Pearson's rho & p-value \\
\hline PPedsQL & 123 & 0.065 & 0.476 & 41 & 0.152 & 0.343 & 82 & 0.021 & 0.853 \\
\hline
\end{tabular}

Table 10a2. By Gender

\begin{tabular}{|c|c|c|c|c|c|c|c|c|c|}
\hline & \multicolumn{9}{|c|}{ CAFAS } \\
\hline & \multicolumn{3}{|c|}{ All } & \multicolumn{3}{|c|}{ Female } & \multicolumn{3}{|c|}{ Male } \\
\hline & $\mathbf{N}$ & Pearson's rho & p-value & $\mathbf{N}$ & Pearson's rho & p-value & $\mathbf{N}$ & Pearson's rho & p-value \\
\hline PPedsQL & 125 & $-0.178^{*}$ & 0.047 & 41 & -0.010 & 0.950 & 84 & $-0.279^{*}$ & 0.010 \\
\hline CPedsQL & 123 & -0.151 & 0.096 & 41 & -0.001 & 0.994 & 82 & $-0.227^{*}$ & 0.040 \\
\hline
\end{tabular}

* significant at the 0.05 level of significance

Table 10b. By Duration of Illness

\begin{tabular}{|c|c|c|c|c|c|c|c|c|c|}
\hline & \multicolumn{9}{|c|}{ Duration of Illness } \\
\hline & \multicolumn{3}{|c|}{ All } & \multicolumn{3}{|c|}{ Female } & \multicolumn{3}{|c|}{ Male } \\
\hline & $\mathbf{N}$ & Pearson's Rho & p-value & $\mathbf{N}$ & Pearson's rho & p-value & $\mathbf{N}$ & Pearson's Rho & p-value \\
\hline PPedsQL & 124 & -0.051 & 0.571 & 40 & 0.042 & 0.796 & 84 & -0.064 & 0.562 \\
\hline CPedsQL & 122 & 0.025 & 0.785 & 40 & 0.270 & 0.091 & 82 & -0.087 & 0.439 \\
\hline CAFAS & 124 & -0.039 & 0.670 & 40 & 0.139 & 0.391 & 84 & -0.127 & 0.251 \\
\hline
\end{tabular}


Table 10c. By Presence of Co-Morbidity

\begin{tabular}{|c|c|c|c|c|c|c|c|c|c|}
\hline & \multicolumn{9}{|c|}{ Child Report PedsQL (CPedsQL) } \\
\hline & \multicolumn{3}{|c|}{ All } & \multicolumn{3}{|c|}{ No co-morbidity } & \multicolumn{3}{|c|}{ At least 1 co-morbidity } \\
\hline & $\mathbf{N}$ & Pearson's Rho & p-value & $\mathbf{N}$ & Pearson's rho & p-value & $\mathbf{N}$ & Pearson's rho & p-value \\
\hline \multirow[t]{4}{*}{ PPedsQL } & 123 & 0.065 & 0.476 & 90 & 0.085 & 0.427 & 33 & 0.041 & 0.822 \\
\hline & \multicolumn{9}{|c|}{ CAFAS } \\
\hline & \multicolumn{3}{|c|}{ All } & \multicolumn{3}{|c|}{ No co-morbidity } & \multicolumn{3}{|c|}{ At least 1 co-morbidity } \\
\hline & $\mathbf{N}$ & Pearson's Rho & p-value & $\mathbf{N}$ & Pearson's rho & p-value & $\mathbf{N}$ & Pearson's rho & p-value \\
\hline PPedsQL & 125 & $-0.178^{*}$ & 0.047 & 92 & -0.134 & 0.205 & 33 & -0.227 & 0.205 \\
\hline CPedsQL & 123 & -0.151 & 0.096 & 90 & -0.078 & 0.462 & 33 & $-0.352^{*}$ & .045 \\
\hline
\end{tabular}

* significant at the 0.05 level of significance

Table 10d. By Duration of Illness \& Co-Morbidity

\begin{tabular}{|c|c|c|c|c|c|c|c|c|c|}
\hline & \multicolumn{9}{|c|}{ Duration of Illness } \\
\hline & \multicolumn{3}{|c|}{ All } & \multicolumn{3}{|c|}{ No co-morbidity } & \multicolumn{3}{|c|}{ At least 1 co-morbidity } \\
\hline & $\mathbf{N}$ & Pearson's Rho & p-value & $\mathbf{N}$ & Pearson's rho & p-value & $\mathbf{N}$ & Pearson's rho & p-value \\
\hline PPedsQL & 124 & -0.051 & 0.571 & 91 & -0.097 & 0.359 & 33 & 0.059 & 0.743 \\
\hline CPedsQL & 122 & 0.025 & 0.785 & 89 & -0.028 & 0.793 & 33 & 0.086 & 0.635 \\
\hline CAFAS & 124 & -0.039 & 0.670 & 91 & -0.069 & 0.519 & 33 & -0.079 & 0.663 \\
\hline
\end{tabular}

Table 11. Agreement between Child \& Parent Report on the Status of the Pediatric Quality of Life

\begin{tabular}{llcc}
\hline & & \multicolumn{2}{c}{ PedsQL Status (Parent Report) } \\
\cline { 3 - 4 } & & $\begin{array}{c}\text { Not Impaired QoL } \\
\text { (n= 48) }\end{array}$ & $\begin{array}{c}\text { Impaired QoL } \\
\text { (n= 75) }\end{array}$ \\
\hline PedsQL Status & Not Impaired QoL & $22(40.0)$ & $33(60.0)$ \\
(Child Report) & Impaired QoL & $26(38.2)$ & $42(61.8)$ \\
\hline
\end{tabular}

- Kappa value is near 0 ,

Table 12. Agreement between Child Report on the Status of the Pediatric Quality of Life \& CAFAS

\begin{tabular}{|c|c|c|c|c|c|}
\hline & & \multicolumn{2}{|c|}{ CAFAS } & \multirow[b]{2}{*}{ Kappa } & \multirow[b]{2}{*}{ p-value } \\
\hline & & $\begin{array}{c}\text { Not Impaired QoL } \\
(\mathrm{n}=7)\end{array}$ & $\begin{array}{c}\text { Impaired QoL } \\
(\mathrm{n}=116)\end{array}$ & & \\
\hline Child's Peds Quality of Life & $\begin{array}{l}\text { Not Impaired QoL } \\
\text { Impaired QoL }\end{array}$ & $\begin{array}{l}1(1.8) \\
6(8.8)\end{array}$ & $\begin{array}{l}54(98.2) \\
62(91.2)\end{array}$ & -0.076 & 0.095 \\
\hline
\end{tabular}

Table 13. Agreement between Parent Report on the Status of the Pediatric Quality of Life \& CAFAS

\begin{tabular}{|c|c|c|c|c|c|}
\hline & & \multicolumn{2}{|c|}{ CAFAS } & \multirow[b]{2}{*}{ Kappa } & \multirow[b]{2}{*}{ p-value } \\
\hline & & $\begin{array}{c}\text { Not Impaired QoL } \\
(\mathrm{n}=7)\end{array}$ & $\begin{array}{c}\text { Impaired QoL } \\
(n=118)\end{array}$ & & \\
\hline \multirow[t]{2}{*}{ Parents Peds Quality of Life } & Not Impaired QoL & $3(6.2)$ & $45(93.8)$ & \multirow{2}{*}{0.013} & \multirow{2}{*}{0.803} \\
\hline & Impaired QoL & $4(5.2)$ & $73(94.8)$ & & \\
\hline
\end{tabular}

that of the clinician's CAFAS assessment of level of functioning (Table 12).

There is minimal positive agreement between the parent PedsQL report and the clinician's CAFAS evaluation. However, this agreement could not be considered as statistically significant (Table 13).

\section{Discussion}

This Philippine study is patterned after the first study of Dr. Bastiaansen et al. on the quality of life in children with psychiatric disorders from three perspectives: child, parent and clinician. This local study, which utilized the linguistically validated Filipino version of the Pediatric Quality of Life Inventory ${ }^{10}$ also looked into the most prevalent child psychiatric conditions and their influence on the children's quality of life as measured by several domains of functioning.

Mental health conditions belonging to both the externalizing and internalizing group of disorders occupied the top three diagnostic categories identified. Attention deficit hyperactivity disorder (ADHD), an externalizing disorder, was the most prevalent psychiatric condition. Anxiety and mood disorders, both internalizing disorders, 
ranked the second and third most common conditions, respectively.

In a Singaporean study that looked into the emotional and behavioural problems of children based on parent, children and teacher report, higher rates of internalizing problems were found, similar to studies in Asia and Africa, but contrary to findings from the West. ${ }^{23}$

As to the most prevalent psychiatric conditions among children and adolescents, the study findings replicate the results of the 2004 Bastiaansen study, but with noted differences. Pervasive developmental disorders (PDD), together with mood disorders, ranked third in prevalence in Dr. Bastiaansen's study. In this local study, children with PDD (autistic disorder with mental retardation) comprised $15 \%$ of consecutive referrals that were excluded from the study.

It is important to note that this Philippine crosssectional data may not be truly reflective of the most prevalent child psychiatric conditions since a significant proportion of children (22\%) with history of abuse were excluded from the study. Moreover, subject selection bias is noted since respondents came from a single institution and sourced from consecutive referrals.

Overall, age and sex findings (e.g., males tended to have ADHD more than females; ADHD patients are younger than patients with mood and psychotic disorders) conform to the expected demographic norm.

Akin Dr. Bastiaansen's study, this Philippine study found few differences in the QoL between children with different child psychiatric disorders from the children's report. In contrast to the Bastiaasen study, Filipino parents rated children without axis I diagnosis (no clinical/mental health conditions) to have the best emotional, social and school (psychosocial) functioning, whereas Filipino parents reported children with externalizing disruptive disorders (oppositional defiant disorder and conduct disorder) to have the poorest psychosocial health.

In the Bastiaansen study, clinicians rated children with pervasive developmental disorder as having the poorer QoL than children with other diagnoses. In this local study, clinicians rated children with psychotic disorders to have the poorest QoL. Comparable to the parents' report, the Filipino clinicians reported children without axis I diagnosis category to have the best overall functioning.

There were no significant differences in the overall QoL across the psychiatric disorders from the perspective of the Filipino child. The Filipino parent, on the other hand, assessed the psychosocial health among the diagnostic categories to significantly differ. Likewise, the Filipino clinician's perspective demonstrated various differences in the overall and the specific domains of functioning among the psychiatric disorders. In the same vein as Dr. Bastiaansen's findings, every diagnostic category affected QoL domains in various aspects.

\section{Attention-Deficit Hyperactivity Disorder (ADHD)}

In terms of school functioning, children with ADHD, like children with psychotic disorders, were more impaired compared to those with parent-child relational problems. In contrast, the Bastiaansen study noted that impairment in school functioning of ADHD children was reported equal to those with anxiety disorders and other disorders. Poorer health-related quality of life was reported for children and adolescents with ADHD. Children with ADHD had more parent-reported problems in terms of emotional/behavioural role function, behavior, mental health, and self-esteem. ${ }^{24}$

According to the clinician scores, children and adolescents with ADHD fared better in mood functioning than those with psychotic disorders. In the Bastiaansen study, clinicians reported more problems in behavior toward others for the ADHD and disruptive behavior group compared to children with anxiety and mood disorders.

\section{Anxiety Disorders}

For children with anxiety disorders, clinicians found more impairment in mood functioning compared with those with parent-child relational problems. Children with anxiety disorders share more impairment in mood functioning together with children who have mood and psychotic disorders.

These results provide additional findings to the Bastiaasen study that established poorer QoL on emotional functioning of children with anxiety disorders compared to other disorders. Moreover, the results of this local study support the premise that the impact of anxiety on QoL is more severe than what has been actually considered. The Bastiaansen study saw the impact on QoL being equal to children with disruptive and mood disorders.

\section{Disruptive Behavior Disorder}

Children with oppositional defiant disorder (ODD) and conduct disorder (CD) have shown poorer functioning in the home and community domains. These children are comparable to those with mood disorders who also did poorly in the home and community domains. These findings were not reflected in the Bastiaansen study as it had disruptive behavior disorder mainly co-morbid with ADHD.

From the parent report, children with disruptive behavior have poorer psychosocial health compared to those without axis I diagnosis. These children have poorer school functioning compared to those with psychotic, no axis I and parent-child relational problem. Moreover, the parent report also identified these children to have poorer social functioning compared with those with psychotic disorders or ADHD.

Parents' poorer rating for children with disruptive behavior than those with psychotic disorder may be due to the externalizing nature of the presenting symptomatologies for ODD and CD. These overtly "disruptive" children can be 
perceived to be difficult to handle compared with the insidious and covert condition of psychotic children. Moreover, children with psychosis may be more likely to go to schools with special education programs.

\section{Mood Disorder}

Based on the clinician's ratings, children with mood disorders had poorer functioning in the community domain except those with children in the disruptive behavior, ADHD, and others categories. Children with mood disorders had higher self-harm scores compared with the rest of the diagnostic categories except children with psychotic disorders.

In the Bastiaansen study, children with mood disorders had a poorer QoL functioning domain compared with children with attention-deficit and disruptive behavior disorder, other disorders or no disorder.

In a study on the quality of life in pediatric bipolar disorder, parents reported that their children exhibited poorer QoL, especially those assessing the psychosocial aspects of QoL. ${ }^{25}$ These youths have a significantly lower QoL on the total score, as well as the physical, emotional, self-esteem, family, friends, and school subscales compared with youth with behaviour disorders or diagnoses other than mood or behaviour disorders.

\section{No Axis I Diagnosis}

In general, children with no axis I diagnosis (those without clinical/mental health conditions) have shown overall better performance across many domains than those belonging to the diagnostic categories of others, disruptive behavior, mood or psychotic disorders. These children have better school functioning compared with the rest except those children with parent-child relational problem. They managed better in the home domain than those with disruptive or mood disorders. They have also shown better mood functioning compared with those with mood or psychotic disorders.

\section{Psychotic Disorder}

Clinicians reported more problems in behavior toward others for the group of children with psychotic disorders compared with children with parent-child relational problems and no axis I diagnosis. They also had the most impairment in the thinking domain compared with the rest of the diagnostic categories.

From the child report, this group of children has poorer QOL in social functioning than those children with disruptive behavior, mood and parent-child relational problem.

From the parent report, children with psychotic disorders had lower emotional functioning compared with those with no axis I diagnosis.
There is a dearth of information on the quality of life of children and adolescents with psychotic disorders. A recent study on adolescents at high risk of developing psychosis had poorer scores in QoL measures. ${ }^{26}$

\section{Parent-Child Relational Problem}

In the Bastiaansen study, relational problem was not among the six diagnostic categories distinguished. Similar to reports from the Great Smoky Mountains Study ${ }^{22}$ on impaired but undiagnosed children and adolescents, this local study shows relational problem to be among the more common childhood disorders.

As to the overall performance across all domains rated by the clinicians, children with parent-child relational problem had less impairment compared with children with mood or psychotic disorders. These children fared better in terms of school functioning (vs. psychotic disorder or ADHD) and mood functioning (vs. anxiety, mood and psychotic disorders).

\section{Correlation and Agreement among Informants' Report}

The inverse correlation finding between CAFAS and PedsQL plausibly highlights what is expected: a higher degree of functional impairment corresponds to a more impaired quality of life. The fact that only the PPEdsQL has shown this correlation to CAFAS can be explained since parents and clinicians are generally considered to be more reliable and objective assessors of the child's health state.

In QoL measurement, besides information from the patient, information from significant others may also be very important, ${ }^{4}$ especially when the patient's perspective may be flawed or distorted by psychiatric symptoms. ${ }^{27}$ However, it is still valuable to get the children's report as this provides understanding of the child's level of insight about his or her health condition. Therapy could be geared towards insight building and acceptance that leads to better adherence to treatment goals.

Another significant finding is that of the inverse correlation of CAFAS to CPedsQL and PPedsQL only among the male children and adolescents. For many pediatric psychiatric conditions, males tend to present overt and disruptive behaviors that lead to earlier recognition of the need for intervention. The male child by virtue of the impact of his externalizing condition to others can be more cognizant of his behavioral problems compared with females. Females, in general, tend to exhibit covert symptoms that serve as a barrier to immediate identification of their disorder.

The last finding is the inverse correlation of the CAFAS to CPedsQL only among those children with at least a single co-morbidity. This can be understood in line with children's growing concrete ability to appreciate the effects when several health conditions already evidently impair their quality of life. 
There was no observed agreement among the three informants: child, parent and clinician. There was minimal positive agreement between parent and clinician, but not statistically significant. This runs contrary to the findings of the Bastiaansen study that showed small (between children and clinicians) to moderate (between child and parents and between parents and clinicians) agreement.

The results underscore that each perspective is different. It reminds all to look into each report to get the totality of the child's quality of life.

\section{Limitations}

Similar to the Bastiaansen et al. study, the tools used to measure quality of life were varied for children/parents (PedsQL) and clinicians (CAFAS). Even if both tools appraised domains of functioning, their items and scales differed. The set cut-off points for an at-risk or impaired quality of life differed between these instruments. Moreover, CAFAS can be linguistically validated to a Filipino version.

\section{Clinical Implications and Significance}

In summary, the Philippine study found the most affected QoL domains as follows: for children with ADHD, school functioning; for children with anxiety disorders, mood functioning; for children with disruptive behavior disorder, home, community domains and social and school functioning; for children with mood disorders, home, community and self-harm domains; for children with psychotic disorder, behavior toward others, mood thinking, and social functioning domains.

All the Philippine results add to what was originally gathered in the Bastiaansen study: for children with ADHD and disruptive behavior disorder, school and social functioning; for children with anxiety disorder, emotional functioning; for children with mood disorders, emotional functioning.

A domain can be specifically affected by a particular diagnostic category and thus can be examined by clinicians as focus of directed intervention. In the assessment as to which child's domain of functioning is most affected, the Philippine study reinforces the recommendation of a multirater, complete data collection to obtain the unique perspectives of the child, parent, and clinician.

As children with disruptive behavior disorders are reported by parents to have the poorest psychosocial health, active measures must be directed for timely screening and intervention for this group. School- and community-based programs can be highly prioritized for immediate identification of these specific children and their families. Effective modules that increase parents' awareness on disruptive behaviors can be keys to prompt referral and management.

Clinicians who assess psychotic children and those with mood disorders to be the most impaired in several domains of functioning must spread their knowledge about the earliest red flags of psychotic behavior through dynamic and sustained liaisons with child care providers. Early detection and treatment are warranted most specially for these identified groups of children. The target goal is to swiftly restore their quality of life at par with children unimpaired by physical or mental health conditions.

Focus and help, however, must also extend to the children with other psychiatric disorders. The study has echoed the time-honored insight that early intervention is critical as seen in the observation that the older the child, the more impaired the quality of life.

Guided efforts (e.g., appropriate school placement, pharmacologic treatment, enrolment in social skills training) geared toward preventing further deterioration in specific domains of functioning of any child must be intensely pursued.

The need for heightened awareness for covert manifestations that herald impaired quality of life and the need for prioritization of effective, evidence-based programs for children with overt signs of psychiatric health conditions still remain to be addressed.

Varied factors or determinants of children's quality of life can still be explored in the Philippines, as well as in the global setting. Each pediatric psychiatric health condition can be independently and comprehensively studied in future research endeavors for the improvement of all children's quality of life.

\section{Acknowledgments}

Deepest appreciation for Dr. Adoracion L. Tanega, Dr. Portia V. Luspo and most especially Dr. Lourdes L. Ignacio for their steadfast guidance and unwavering support for this study. To Dr. Vincent Lu, Dr. Ces Acuin and Mr. Ruel Guirindola, many thanks for all the extended help.This paper has been recipient of the NIH Pfizer Research Fellowship Program Grant Year II.

\section{References}

1. Bastiaansen D, Koot HM, Ferdinand RF, Verhulst FC. Quality of life in children with psychiatric disorders: self-, parent and clinician report. J Am Acad Child Adolesc Psychiatry. 2004; 43(2):221-30.

2. Sawyer MG, Whaites L, Rey JM, Hazell PL, Graetz BW, Baghurst P. Health-related quality of life of children and adolescents with mental disorders. J Am Acad Child Adolesc Psychiatry. 2002; 41(5):530-7.

3. Schmeck K, Poustka F. Quality of life and child psychiatric disorders. In: Katschnig H, Freeman H, Sartorius N, eds. Quality of Life in Mental Disorders. Chichester, England: Wiley; 1997. pp. 179-191.

4. Wallander JL, Schmitt M, Koot HM. Quality of life measurement in children and adolescents: issues, instruments and applications. J Clin Psychol. 2001; 57(4):571-85.

5. Lehman AF. A quality of life interview for the chronically mentally ill. Eval Program Plann. 1988; 11:51-62.

6. Mogotsi M, Kaminer D, Stein DJ. Quality of life in the anxiety disorders. Harv Rev Psychiatry. 2000; 8(6):273-82. 
7. Loonen HJ, Derkx BH, Otley AR. Measuring health-related quality of life of pediatric patients. J Pediatr Gastroenterol Nutr. 2001; 32(5):523-6.

8. Varni JW, Barwinkle TM, Seid M, Skarr D. The PedsQL 4.0 as a pediatric population health measure: feasibility, reliability and validity. Ambul Pediatr. 2003; 3(6):329-41.

9. Bastiaansen D, Koot HM, Bongers IL, Varni JW, Verhulst FC. Measuring quality of life in children referred for psychiatric problems: Psychometric properties of the PedsQL 4.0 Generic Core Scales. Qual Life Res. 2004; 13(2):489-95.

10. Malinit JP. Quality of Life in Children with Psychiatric Disorders: a Validation Study of the Pediatric Quality of Life Inventory Version 4.0 (PedsQL) at Philippine Children's Medical Center. Quezon City: Philippine Children's Medical Center. Philippine Children's Medical Center Journal. 2006; 15-22.

11. Varni JW, Seid M, Kurtin PS. PedsQL 4.0: Reliability and validity of the Pediatric Quality of Life Inventory Version 4.0 Generic Core Scales in healthy and patient populations. Med Care. 2001; 39(8):800-12.

12. Pediatric Quality of Life Inventory Version 4.0. [Online]. 2001 [cited 2005 Jan]. Available from http://www.pedsql.org/

13. Hodges K, Wong MM. Psychometric Characteristics of a Multidimensional Measure to Assess Impairment: the Child and Adolescent Functional Assessment Scale. J Child Fam Studies. 1996; 5(4):445-67.

14. Hodges K. CAFAS Manual for Training Coordinators, Clinical Administrators and Data Managers. Available from Dr. K. Hodges, 2140 Old Earhart Road, Ann Arbor, MI 48105; 1997.

15. Waslick B, Greenhil L. Attention Deficit Hyperactivity Disorder In: Wiener J, Dulcan M, eds. Textbook of Child and Adolescent Psychiatry, $3^{\text {rd }}$ ed. Arlington, Virginia: American Psychiatric Publishing, Inc.; 2004. p.492.

16. Sadock BJ, Sadock VA. Kaplan \& Sadock's Synopsis of Psychiatry. Philadelphia: Lippincott Williams \& Wilkins; 2007.

17. Lewinsohn PM, Gotlib IH, Lewinsohn M, Seeley JR, Allen NB. Gender differences in anxiety disorders and anxiety symptoms in adolescents. J Abnorm Psychol. 1998; 107(1):109-17.

18. Meltzer H, Gatward R, Goodman R, Ford T. Mental health of children and adolescents in Great Britain. Int Rev Psychiatry. 2003; 15(1-2):185-7.

19. Cohen P, Cohen J, Kasen S, et al. A epidemiologic study of disorders in late childhood and adolescence-I: Age and gender specific prevalence. J Child Psychol Psychiatry. 1993; 34(6):851-67.

20. Hankin BL, Abramson LY, Motfitt TE, Silva PA, McGee R, Angell KE. Development of depression from preadolescence to young adulthood: emerging gender differences in a 10-year longitudinal study. J Abnorm Psychol. 1998; 107(1):128-40.

21. Tsai L, Champine D. Schizophrenia and Other Psychotic Disorders. In: Wiener J, Dulcan M, eds. Textbook of Child and Adolescent Psychiatry, $3^{\text {rd }}$ ed. Arlington, Virginia: American Psychiatric Publishing, Inc.; 2004. p.380.

22. Angold A, Cosrello EJ, Farmer EM, Burns BJ, Erkanli A. Impaired but undiagnosed. J Am Acad Child Adolesc Psychiatry. 1999; 38(2):129-37.

23. Woo BS, Ng TP, Fung DS, et al. Emotional and behavioural problems in Singaporean children based on parent, teacher and child reports. Singapore Med J. 2007; 48(12):1100-6.

24. Klassen AF, Miller A, Fine S. Health-related quality of life in children and adolescents who have a diagnosis of attention-deficit/hyperactivity disorder. Pediatrics. 2004; 114(5):e541-7.

25. Freeman AJ, Youngstrom EA, Michalak E, Siegel R, Meyers OI, Findling RL. Quality of life in pediatric bipolar disorder. Pediatrics. 2009; 123(3):446-52.

26. Grano N, Karjalainen M, Suominen K, Roine M. Poor functioning ability is associated with high risk of developing psychosis in adolescents. Nord J Psychiatry. 2011; 65(1):16-21

27. Sainfort F, Becker M, Diamond R. Judgments of quality of life of individuals with severe mental disorders: patient self-report versus provider perspectives. Am J Psychiatry. 1996; 153(4):497-502. 